\title{
Synthesis of low-molecular-weight telechelic polyisobutylene
}

\author{
E. Walch and R. J. Gaymans* \\ Twente University of Technology, Polymer Chemistry, PO Box 217, 7500 AE Enschede, \\ The Netherlands \\ (Received 10 February 1992)
}

\begin{abstract}
Telechelic polyisobutylene with chlorine end-groups was made by cationic polymerization of isobutylene in methylene chloride with difunctional initiators (2,5-dimethoxy-2,5-dimethylhexane and 2,5-diacetyl-2,5dimethylhexane). The structure of these initiators resembles that of polyisobutylene. $\mathrm{BCl}_{3}$ and $\mathrm{TiCl}_{4}$ were used as catalysts. The molecular weight of these telechelics was varied between 600 and $3500 \mathrm{~g} \mathrm{~mol}^{-1}$, with a molecular-weight distribution ranging from 1.3 to 2.1 . The materials were characterized by high-performance liquid chromatography, nuclear magnetic resonance and infra-red spectroscopy.
\end{abstract}

(Keywords : telechelic polymers; polyisobutylene; 2,5-dimethoxy-2,5-dimethylhexane; $\mathrm{BCl}_{3}$; synthesis; characterization)

\section{INTRODUCTION}

The first reported synthesis of polyisobutylene dates from $1873^{1}$. It was made by heating isobutylene monomer (IB) in the presence of strong acids. With this method only low-molecular-weight oligomers with one functional end-group could be made. Later it was discovered that the molecular weight could be increased considerably by lowering the temperature of the synthesis down to $-75^{\circ} \mathrm{C}^{2}$.

\section{TELECHELIC POLYISOBUTYLENE}

An alternative way to use polyisobutylene (PIB) is not as a homopolymer, but as a segment in a block copolymer. If PIB is to be used as a soft block in a copolymer, it is necessary that it can be polymerized in a controlled way such that it gets defined end-groups that are reactive or can be converted to reactive end-groups. There are two different processes known to make block copolymers. One is living polymerization, where a two- or three-block copolymer is made of isobutylene and a second monomer in one pot by successively adding the components; for example, the polymerization of isobutylene followed by that of $\alpha$-methylstyrene ${ }^{3}$. A second way is to make a difunctional oligomer that is polymerized in a second step to a block copolymer. This second step is normally a condensation polymerization. The difunctional oligomers that are used usually have molecular weights in the range of $500-5000 \mathrm{~g} \mathrm{~mol}^{-1}$.

\section{Initiating system}

The literature reports different methods for the

\footnotetext{
*To whom correspondence should be addressed
}

synthesis of difunctional PIB. Some of them start from the monomers ${ }^{4}$, while others make the oligomers from high-molecular-weight polymer ${ }^{5}$. Kennedy ${ }^{3,6,7}$ has shown that it is possible to make dichloro-terminated oligomers by using special difunctional initiators. The main structure of these initiators that will form a carbocation with a Lewis acid are:<smiles>[R]C(C)(C)Cl</smiles><smiles>[R]C(C)(C)OC</smiles><smiles>[R]C(C)(C)OC(C)=O</smiles>

$\mathrm{R}$ may be an alkyl or aryl group. In the case when a difunctional initiator is needed, $R$ must have two of these functional groups. The initiators form stable tertiary carbocations, while the functional group and the Lewis acid together form the anion.

The best initiators are those which initiate easily so that less reactive catalysts can be used. These catalysts will initiate slowly or not at all with impurities. The best-described initiators are 1,4-dicumyl chloride ${ }^{3}$ and the ether ${ }^{8,9}$ or ester derived from it. A disadvantage of this initiator is that rather low temperatures are necessary for the synthesis. At temperatures above $-60^{\circ} \mathrm{C}$ the growing chain can react with the aromatic ring of the initiator with the formation of indanyl structures ${ }^{10}$. This arylation will not happen with aliphatic initiators, so that temperatures up to $0^{\circ} \mathrm{C}$ can be used ${ }^{11}$. Aliphatic initiators with a chlorine functionality are poor initiators ${ }^{12}$.

This reaction is catalysed by Lewis acids ${ }^{13}$. The reactivity for the polymerization decreases in the order: $\mathrm{AlCl}_{3}>\mathrm{BF}_{3}>\mathrm{AlBr}_{3}>\mathrm{TiCl}_{4}>\mathrm{TiBr}_{4}>\mathrm{BCl}_{3}>$ $\mathrm{BBr}_{3}>\mathrm{SnCl}_{4}$. A catalyst that is too reactive is less 
suitable as it will easily form an initiating complex with traces of impurities and will give chain transfer at higher temperatures. It was also found that a very reactive catalyst like $\mathrm{AlCl}_{3}$ can use the solvent $\mathrm{CH}_{2} \mathrm{Cl}_{2}$ as an initiator ${ }^{14}$. This is, however, undesired, as it will lead to monofunctional polymers. This initiating effect was, however, not observed with Lewis acids less reactive than $\mathrm{AlCl}_{3}$. Lewis acids stronger than $\mathrm{BCl}_{3}$ will initiate polymerization in the presence of traces of water ${ }^{15}$, giving monofunctional polymers.

With $\mathrm{BCl}_{3}$ in methylene chloride the initiation with water will go slowly, so that the initiation of water relative to an aliphatic ester ${ }^{16}$ or ether ${ }^{8}$ catalyst is slow. With $\mathrm{BCl}_{3}$ the chain transfer in methylene chloride is very slow, even at temperatures above $-60^{\circ} \mathrm{C}$. For these two reasons boron trichloride is very suitable to carry out the reaction at temperatures above $-60^{\circ} \mathrm{C}$.

The telechelics made with the above-described difunctional initiator and $\mathrm{BCl}_{3}$ are chlorine end-capped with the chlorine at a tertiary carbon atom. Another way to proceed with this end-group is to remove the chlorine as hydrogen chloride. In this case an olefinic end-group is formed to which other different reactive components can be added ${ }^{17-21}$.

The reaction can be initiated with water but the resulting polymer then has only one functional end-group. The other end bears an inert head-group. If all traces of water are removed and a difunctional initiator is added, both ends will start growing, and at the end of the reaction two chlorine end-groups are obtained. The initiation with the difunctional initiator is similar to that with water. The initiator molecule is only much bigger than $\mathrm{H}_{2} \mathrm{O}$.<smiles>COC(C)(C)CCC(C)(C)OC</smiles>

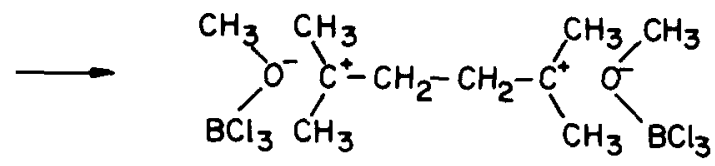

This activated initiator will now start a polymerization in the same way as the water-initiated system. Only the anion-cation complex of the polymerizing chain is different with the different initiators. With water a $\mathrm{BCl}_{3} \cdot \mathrm{OH}^{-}$anion is formed, while the above ether initiator gives $\mathrm{BCl}_{3} \cdot \mathrm{OCH}_{3}^{-}$as an anion. Initiators with ester functionalities can also be used. They will give $\mathrm{BCl}_{3} \cdot \mathrm{OCOCH}_{3}^{-}$as anions. In the literature it is claimed that the initiator with an ether ${ }^{8}$ or an ester ${ }^{2,23}$ functionality gives living polymers in the presence of $\mathrm{BCl}_{3}$.

\section{Termination}

In the termination reaction with PIB it is difficult to get an end-group other than the $\mathrm{Cl}$ from catalyst. This is in contrast to most other ionic polymerizations, where the end-group is determined by the quenching agent.

It was the aim of our study to synthesize reactive, difunctional PIB oligomers in the molecular-weight range of 500-5000 with a method described by Kennedy.

\section{EXPERIMENTAL}

\section{Materials}

Methylene chloride (Merck, stabilized with 2-methyl1-butene) was refluxed for $24 \mathrm{~h}$ over $\mathrm{CaH}_{2}$ and then distilled and stored over sodium wire.

Isobutylene (Ucar) was passed through columns filled with $\mathrm{BaO}$ and molecular sieves to dry it and was then condensed into the reaction vessel.

Boron trichloride (Ucar), titanium tetrachloride (Merck), methanol (Merck) and 2,5-dihydroxy-2,5dimethylhexane (Fluka) were all used as received.

\section{Analytical techniques}

High-performance liquid chromatography. The polymers were characterized with a Waters HPLC. The HPLC was provided with 100,500 and $1000 \AA$ Styragel columns and an RI detector. The system was calibrated with polystyrene. The determined molecular masses were therefore not accurate and the h.p.l.c. results were mainly used to establish the polydispersity of the PIB samples. Measurements were all carried out with $10 \mathrm{~g} \mathrm{l}^{-1}$ solutions of the telechelic in tetrahydrofuran (THF) at an operating speed of $2 \mathrm{ml} \mathrm{min}-1$.

Infra-red analysis. A Perkin-Elmer 1310 IR and a Biorad 60 FTIR were used for infra-red analyses of the PIB telechelics. The viscous telechelics were put as a paste on one side of an $\mathrm{NaCl}$ plate.

Nuclear magnetic resonance. End-groups of the telechelics were studied with a Bruker $80 \mathrm{MHz}$ apparatus. Solutions of 5-10\% telechelic in d-chloroform were used. Tetramethylsilane (TMS) was used as an internal reference. The samples were scanned 100 times to reduce the noise.

\section{Initiator synthesis}

2,5-Dimethyl-2,5-hexane diacetate. The synthesis was carried out according to a similar synthesis of t-butyl acetate in Vogel $^{24}$. To $100 \mathrm{~g}$ 2,5-dihydroxy-2,5-dimethylhexane (Fluka) was added $300 \mathrm{ml}$ of acetic acid anhydride (Fluka). After all the anhydride had been added, the mixture was heated to the reflux temperature. When all the 2,5-dihydroxy-2,5-dimethylhexane had dissolved, $1 \mathrm{~g} \mathrm{SnCl}_{2}$ was added as a catalyst. This mixture was held at refiux temperature for $2 \mathrm{~h}$ and then cooled to room temperature. The acetic acid formed was distilled off at $125-130^{\circ} \mathrm{C}$. After the distillation of the acetic acid, the pressure was reduced and the excess of anhydride was removed at $40-50^{\circ} \mathrm{C}(20 \mathrm{mmHg})$. The residue was dissolved in $100 \mathrm{ml}$ ether and washed with $100 \mathrm{ml}$ water. After separation of the water layer, the ether was evaporated and the product was distilled $\left(121^{\circ} \mathrm{C}\right.$, $22 \mathrm{mmHg}$ ). The yield was $44.7 \mathrm{~g} 2,5$-dimethyl-2,5-hexane diacetate $(27.6 \%)$.

The analysis with n.m.r. showed three peaks: $-\mathrm{CH}_{2}$ $1.73 \mathrm{ppm} ;-\mathrm{CH}_{3} 1.34 \mathrm{ppm}$; $-\mathrm{OCOCH}_{3} 1.87 \mathrm{ppm}$. The synthesis of this initiator was described earlier ${ }^{25}$, but with a different method, and no yield or physical data were given.

2,5-Dimethyl-2,5-dimethoxyhexane. To $100 \mathrm{~g}$ diol (2,5-dihydroxy-2,5-dimethylhexane) $15 \mathrm{~g}$ sodium was added. This mixture was intensively stirred for $7 \mathrm{~h}$ at $140^{\circ} \mathrm{C}$ and cooled to room temperature. The unreacted 
sodium was removed and $55 \mathrm{ml} \mathrm{MeI}$ was added. The temperature rose several degrees after the MeI addition. After $3.5 \mathrm{~h} 100 \mathrm{ml}$ hexane was added to dissolve the product. The mixture was now filtered and a liquid product remained when all the hexane was vaporized. By comparing the peak at $1.22 \mathrm{ppm}$ from the $-\mathrm{CH}_{3}$ near the hydroxyl group and the peak at $3.18 \mathrm{ppm}$ from the $-\mathrm{CH}_{3}$ near the ether group in the n.m.r. spectrum, it was established that this product contained about two-thirds monoether and one-third diol.

The above-mentioned synthesis was repeated twice with the product of the previous synthesis. First it was repeated with $9 \mathrm{~g} \mathrm{Na}$ and $28 \mathrm{ml} \mathrm{MeI}$, and then a second time with $7 \mathrm{~g} \mathrm{Na}$ and $14 \mathrm{ml} \mathrm{MeI.} \mathrm{N.m.r.} \mathrm{analysis} \mathrm{showed}$ that after three repeated reaction cycles most of the diol was converted to the diether. The results of this synthesis are given in Table 1 . The total yield was $37 \%$. The liquid product obtained after the third cycle was distilled at $85^{\circ} \mathrm{C}(18 \mathrm{mmHg})$. In a second initiator synthesis the products of the first cycle were extracted with chloroform. In this way more unreacted diol from the first cycle was used in the second reaction cycle and the total yield became higher ( $59 \%$ after distillation).

N.m.r. analysis showed three peaks : $-\mathrm{CH}_{2}-1.49 \mathrm{ppm}$; $-\mathrm{CH}_{3} 1.15 \mathrm{ppm} ;-\mathrm{OCH}_{3} 3.18 \mathrm{ppm}$. A synthesis of this initiator was not found in the literature.

\section{Telechelic polyisobutylene synthesis}

The synthesis was carried out in glass equipment that was dried overnight in an oven at $120^{\circ} \mathrm{C}$ and then mounted together while it was still hot. It was flushed with nitrogen gas and when it had reached room temperature the glass vessel was immersed in a cooling bath of -30 to $-40^{\circ} \mathrm{C}$. The isobutylene was condensed into this $250 \mathrm{ml}$ flask for 0.5 to $2 \mathrm{~h}$. During the condensation, the gas flow was measured with a calibrated flowmeter. When the required amount of IB was condensed, $150 \mathrm{ml}$ precooled methylene chloride $\left(-20^{\circ} \mathrm{C}\right)$ was added under stirring. The mixture was given $10 \mathrm{~min}$ to cool further to the temperature of the cooling bath. After these $10 \mathrm{~min}$ the initiator or initiator solution and $50 \mathrm{ml}$ precooled $1 \mathrm{~mol}^{-1} \mathrm{BCl}_{3}$ solution in methylene chloride $\left(-20^{\circ} \mathrm{C}\right)$ were added successively.

Table 1 Synthesis of 2,5-dimethyl-2,5-dimethoxyhexane in three cycles

\begin{tabular}{llll}
\hline & $\begin{array}{l}\text { Diol } \\
(\mathrm{mol})\end{array}$ & $\begin{array}{l}\text { Monoether } \\
(\mathrm{mol})\end{array}$ & $\begin{array}{l}\text { Diether } \\
(\mathrm{mol})\end{array}$ \\
\hline Start & 0.68 & - & - \\
1st cycle & 0.12 & 0.30 & - \\
2nd cycle & - & 0.19 & 0.14 \\
3rd cycle & - & 0.02 & 0.23 \\
\hline
\end{tabular}

Table 2 Polymerization with different catalysts

\begin{tabular}{llll}
\hline Catalyst & $\begin{array}{l}\text { Temperature } \\
\left({ }^{\circ} \mathrm{C}\right)\end{array}$ & $\begin{array}{l}\text { Unsaturation (i.r.) } \\
\text { peak ratio }\end{array}$ & $\begin{array}{l}\text { Chlorine (n.m.r.) } \\
\mathrm{CH}_{\mathbf{3}} \text { end } / \mathrm{CH}_{\mathbf{3}} \text { bulk }\end{array}$ \\
\hline $\mathrm{TiCl}_{4}{ }_{\mathrm{CiCl}_{4}{ }^{b}}$ & -40 & 0.44 & 0.005 \\
$\mathrm{TiCl}_{4}{ }^{\circ}$ & -40 & 0.36 & 0.000 \\
$\mathrm{BCl}_{3}$ & -80 & 0 & 0.016 \\
\hline
\end{tabular}

${ }^{a}$ Ratio between infra-red peaks at 895 and $930 \mathrm{~cm}^{-1}$

${ }^{b}$ With ester-type initiator. The initiator/monomer ratios were chosen to give a molecular weight of 2000
The $\mathrm{BCl}_{3}$ solution was added fast under intensive mixing with a magnetic stirrer. The reaction was allowed to proceed for $1 \mathrm{~h}$. Then the polymer was quenched by adding $10 \mathrm{ml}$ methanol to the reaction flask. After quenching, more methanol was added to precipitate all the PIB. The polymer precipitated as a viscous liquid. The exact amount of condensed isobutylene was now calculated by weighing the reaction vessel with the precipitated polymer. This calculation afterwards was carried out because not all the IB that went through the flowmeter may have been condensed.

Most of the methylene chloride was removed with a Rotavapor. After this the polymer was washed a few times with fresh methanol by adding methanol and then decanting it. The remaining methanol was removed with a Rotavapor at $30^{\circ} \mathrm{C}$. Care was taken to make sure that the temperature stayed low, as at higher temperatures the chlorine could evolve as $\mathrm{HCl}$.

\section{RESULTS AND DISCUSSION}

\section{Influence of catalyst}

$\mathrm{BCl}_{3}$ as well as $\mathrm{TiCl}_{4}$ have been used as a catalyst under identical conditions. Titanium chloride is a stronger Lewis acid than $\mathrm{BCl}_{3}$. Because of this it will more easily form an initiating complex with impurities like water, and the stronger cation will also give chain transfer more easily. Both effects are undesirable because this will give monofunctional chains. The experiments with $\mathrm{TiCl}_{4}$ were carried out at -40 and $-80^{\circ} \mathrm{C}$. The syntheses at $-40^{\circ} \mathrm{C}$ gave products with peaks at $895 \mathrm{~cm}^{-1}$ in the i.r. spectrum, which means that it contained unsaturated groups (Table 2). The unsaturation was not found if $\mathrm{BCl}_{3}$ was used. An experiment carried out at $-80^{\circ} \mathrm{C}$ with $\mathrm{TiCl}_{4}$ as catalyst did not show any unsaturation, but the chlorine content of this telechelic was much lower than would be expected on the basis of the initiator/monomer ratio as shown in Table 2. The ratio of end-groups to bulk groups should be 0.056 under the chosen conditions. This means that only a few of the end-groups contained a chlorine atom. The nature of the other groups was not examined. Based on these results and the good results obtained with $\mathrm{BCl}_{3}$ (values close to the theoretical 0.056 ) it was decided to use only $\mathrm{BCl}_{3}$ as a catalyst.

\section{Influence of initiator type}

The dimethyl ether and the diacetic acid ester of 2,5-dimethyl-2,5-hexanediol were examined as initiators for isobutylene polymerization. The above aliphatic initiators were chosen as initiators because their structure

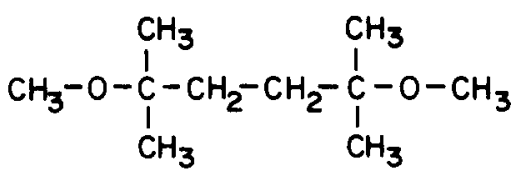

2,5-dimethyl-2,5-dimethoxyhexane<smiles>CC(=O)OC(C)(C)CCC(C)(C)OC(C)=O</smiles>

2,5-dimethyl-2,5-hexanediacetate 
resembles that of polyisobutylene. The use of the dimethyl ether has not been reported before. The diacetate was previously used by Kennedy ${ }^{25}$.

Another reason for the use of an aliphatic initiator is the absence of side-reactions like indanyl ring formation that can occur when aromatic rings are present in the initiator part. The molecular-weight distribution of polymers initiated with the different initiators is given in Figure 1 and Table 3 together with the results of an experiment without initiator.

Figure 1 and Table 3 show that the ester initiator gives a molecular-weight distribution that is much broader than the corresponding ether initiator. A broad distribution for this ester-type initiator was also found by Kennedy ${ }^{26}$. The reason for a broad distribution is a low ratio between the initiation and polymerization rates.

The experiment with adding only the catalyst and no initiators shows that, without initiator, polymerization still occurs and is probably initiated by impurities. This polymer had a high molecular weight.

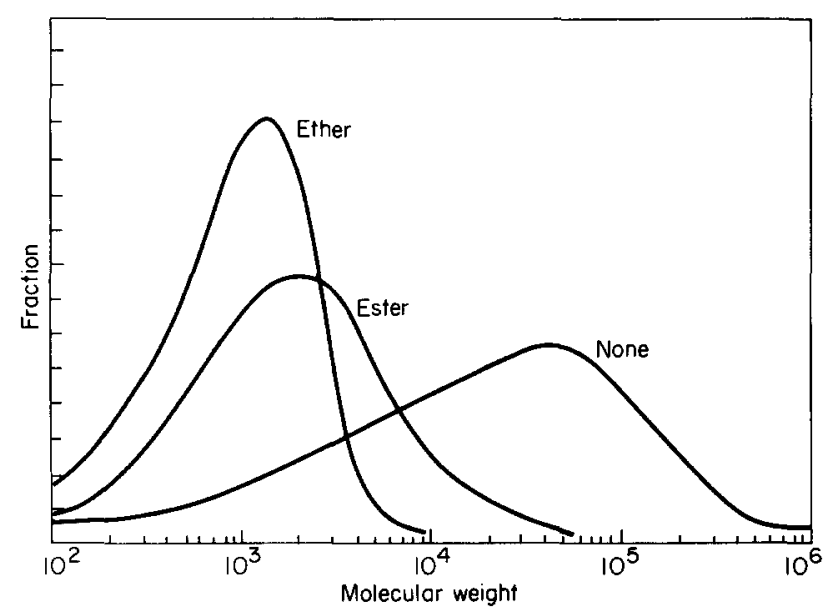

Figure 1 Molecular-weight distribution with different initiators: $[\mathrm{I}]=0.1 \mathrm{~mol} \mathrm{l}^{-1} ;[\mathrm{IB}]=2.0 \mathrm{~mol} \mathrm{l^{-1 }} ;\left[\mathrm{BCl}_{3}\right]=0.25 \mathrm{~mol} \mathrm{l}^{-1}$; $T=-30^{\circ} \mathrm{C}$ (h.p.l.c. with PS calibration)

Table 3 Telechelic synthesis with different initiators $\left([\mathrm{I}]=0.1 \mathrm{~mol} \mathrm{l}^{-1},[\mathrm{IB}]=2.0 \mathrm{~mol} \mathrm{l^{-1 }},\left[\mathrm{BCl}_{3}\right]=0.25 \mathrm{~mol} \mathrm{l}^{-1}\right)$

\begin{tabular}{llllc}
\hline Sample & Initiator type & $\begin{array}{l}M_{\mathrm{n}} \\
\text { (theoretical) }\end{array}$ & $\begin{array}{l}M_{\mathrm{n}} \\
\text { (h.p.l.c.) }\end{array}$ & $\begin{array}{c}M_{\mathrm{w}} / M_{\mathrm{n}} \\
\text { (h.p.l.c.) }\end{array}$ \\
\hline PIB 1 & Ester & 1385 & 1160 & 3.4 \\
PIB 2 & Ether & 1711 & 670 & 2.0 \\
PIB 3 & None & $\infty$ & 5250 & 11.4 \\
\hline
\end{tabular}

Table 4 PIB synthesis. Influence of the initial concentrations on the reaction yield (reaction in $\mathrm{CH}_{2} \mathrm{Cl}_{2}$ at $-30^{\circ} \mathrm{C}$ and 2,5-dimethyl-2,5dimethoxyhexane as initiator)

\begin{tabular}{lllllr}
\cline { 3 - 5 } & $\begin{array}{l}{[\mathrm{IB}]} \\
\left(\mathrm{mol} \mathrm{1}^{-1}\right)\end{array}$ & $\begin{array}{l}{\left[\mathrm{BCl}_{3}\right]} \\
\left(\mathrm{mol} \mathrm{1}^{-1}\right)\end{array}$ & $\begin{array}{l}{[\text { init. }} \\
\left.(\mathrm{mol} \mathrm{1})^{-1}\right)\end{array}$ & $\begin{array}{l}{[\text { init. }] /\left[\mathrm{BCl}_{3}\right]} \\
\text { ratio }\end{array}$ & $\begin{array}{l}\text { Yield } \\
(\%)\end{array}$ \\
\hline PIB 1 & 2.0 & 0.09 & 0.11 & 1.22 & 0 \\
PIB 2 & 2.1 & 0.25 & 0.08 & 0.32 & $>90$ \\
PIB 3 & 2.0 & 0.25 & 0.05 & 0.20 & $>90$ \\
PIB 4 & 2.0 & 0.25 & 0.10 & 0.40 & $>90$ \\
PIB 5 & 2.0 & 0.25 & 0.05 & 0.20 & $>90$ \\
PIB 6 & 2.0 & 0.25 & 0.10 & 0.40 & $>90$ \\
PIB 7 & 2.0 & 0.25 & 0.10 & 0.40 & $>90$ \\
PIB 8 & 2.0 & 0.25 & 0.20 & 0.80 & $>90$ \\
PIB 9 & 2.0 & 0.50 & 0.20 & 0.40 & \\
\hline
\end{tabular}

Because the diether gave the narrower molecularweight distribution, it was decided to use 2,5-dimethyl2,5-dimethoxyhexane for the polymerizations. Unless otherwise stated the reactions were carried out in the same way as PIB 2.

\section{Influence of initiator/catalyst ratio}

The initiator/catalyst ratio was changed to evaluate the influence of this ratio on the polymerization (Table 4 ). The ratio was changed between 0.2 and 1.22 . Low ratios seemed to have no effect on the yield, which was always above $90 \%$ up to an initiator $/ \mathrm{BCl}_{3}$ ratio of 0.5 . At higher ratios no polymer at all was obtained within $2 \mathrm{~h}$ of reaction.

A ratio above 0.5 means that there were more ether groups from the initiator than there were $\mathrm{BCl}_{3}$ groups to form a complex with them. This ratio was specific for this ether initiator; with the ester type of initiator, polymerization took place at all ratios. The uncomplexed ether groups that are present in the case of a ratio above 0.5 seem to inhibit the polymerization in some way. It is known from the work of Polanyi et al. ${ }^{27}$ that diethyl ether acts as an inhibitor in polyisobutylene polymerization. This inhibition might be one reason for the fact that the molecular-weight distribution with the ether is smaller than with the ester type of initiator. The polymerization does not start immediately but only after the activation of most of the initiator.

\section{Molecular-weight distribution}

The molecular-weight distributions that were found with the ether initiator are equal to or lower than 2.0. Only the telechelics made with the ester type of initiator gave broader distributions, as mentioned before (Figure 1). In Figure 2 is the molecular-weight distribution $\left(M_{\mathrm{w}} / M_{\mathrm{n}}\right)$ plotted against the molecular weight $\left(M_{\mathrm{n}}\right)$. One sees a narrowing of the molecular-weight distribution with increasing molecular weight, as would be expected for living polymer systems. This narrowing is caused by the fact that the initiation time becomes less significant at longer chain lengths.

\section{Continuous monomer addition}

Isobutylene was polymerized with continuous monomer addition to examine the living character of the polymerization. This polymerization was carried out by

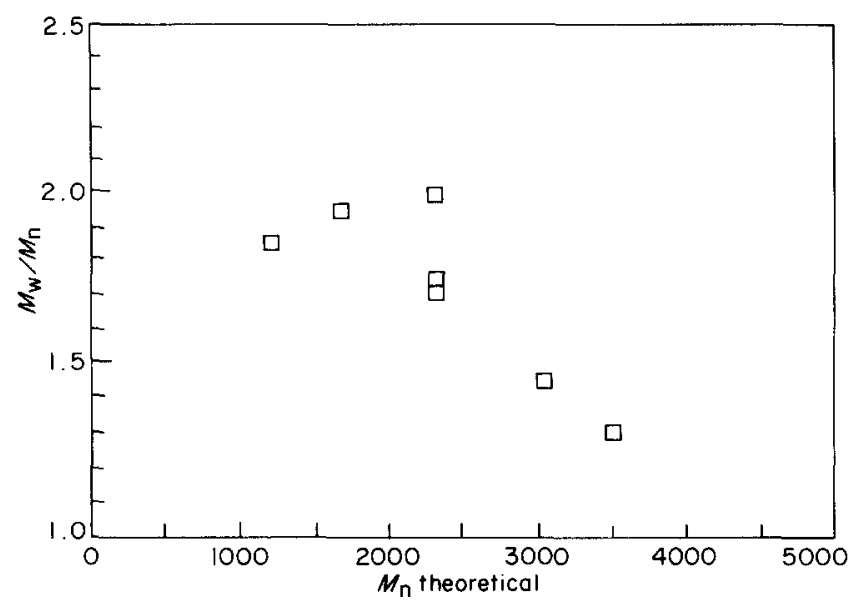

Figure 2 Change of molecular-weight distribution as a function of the theoretical $M_{\mathrm{n}}:[\mathrm{IB}]=2.0 \mathrm{~mol} 1^{-1} ;\left[\mathrm{BCl}_{3}\right]=0.25 \mathrm{~mol} \mathrm{l}^{-1}$; $T=-30^{\circ} \mathrm{C}$ 
condensing a continuous stream of monomer into a reaction vessel with methylene chloride in it as a solvent. At $15 \mathrm{~min}$ after the start of the condensation the initiator and the catalyst were added. The monomer addition was continued over the next $3 \mathrm{~h}$. At certain time intervals samples were taken from the reaction vessel with a syringe and then put in flasks filled with methanol. The bulk volume and concentration were corrected for the withdrawn sample volume. After standing overnight the methanol was decanted from the viscous polymer. The polymer was rinsed with fresh methanol and then dried in a vacuum oven. From the weight of the samples the amount of polymer that had been formed in the reaction flask could be calculated. The results are presented in Figure 3. The molecular-weight distribution of these samples was examined with h.p.l.c. These results are presented in Figure 4.

Figure 3 shows a linear increase of the formed polymer mass with time. This linear increase means that the polymerization is fast enough to polymerize immediately all the freshly added monomer. After about $1 \mathrm{~h}$ of

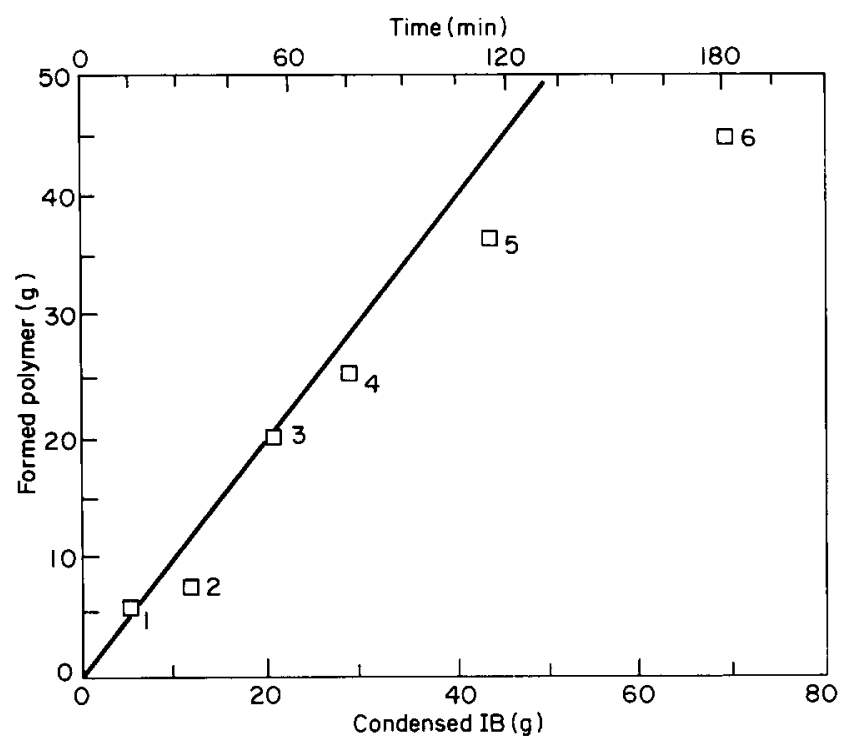

Figure 3 Yield as a function of time. The straight line represents a case of $100 \%$ conversion. Numbers are sample numbers (see also Figure 4). Used conditions were: $100 \mathrm{ml} \mathrm{CH}_{2} \mathrm{Cl}_{2}, 8 \mathrm{mmol}$ initiator, $0.16 \mathrm{~mol}$ $\mathrm{BCl}_{3}, T=-30^{\circ} \mathrm{C}$

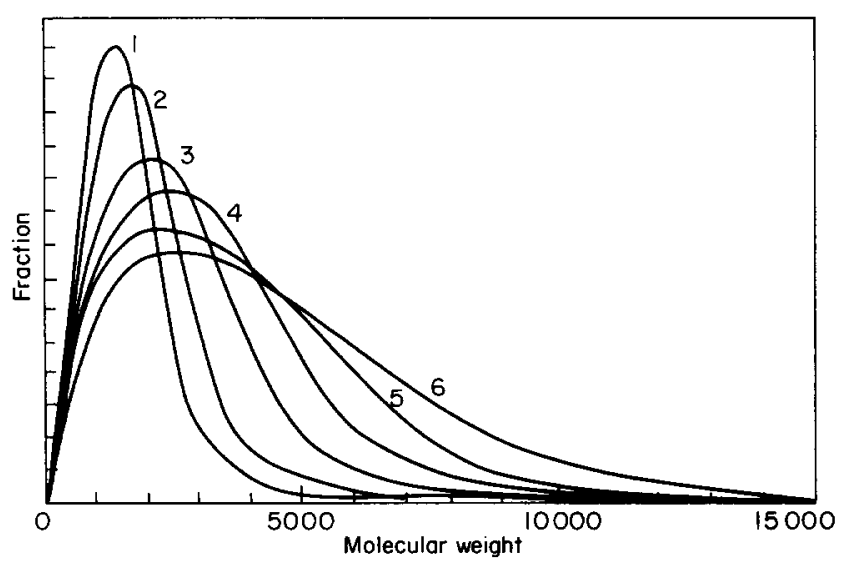

Figure 4 Molecular-weight distribution as a function of polymerization time. Continuous monomer addition. The numbers correspond with sample numbers in Figure 3 (h.p.l.c. with PS calibration)

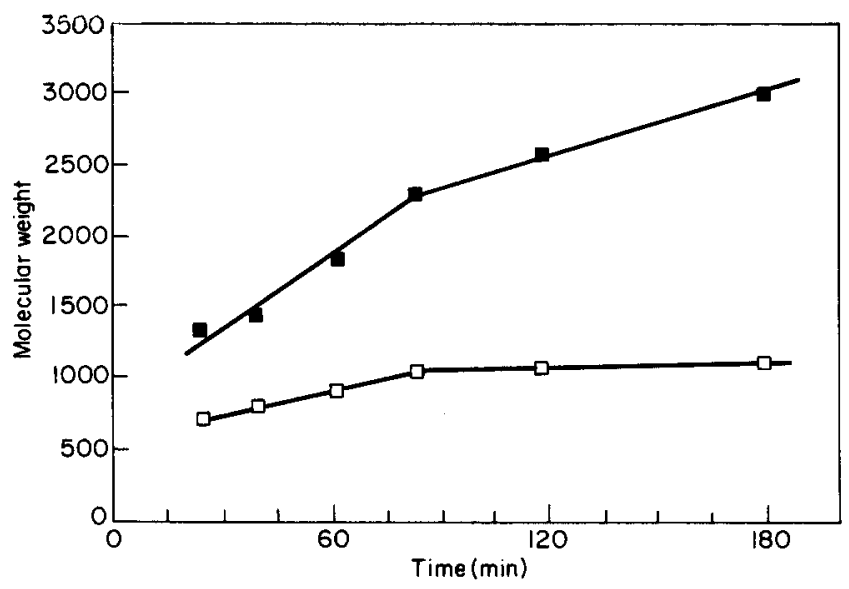

Figure 5 Change of molecular weight during constant monomer addition as determined with h.p.l.c. : $\square, M_{\mathrm{n}} ; \boldsymbol{\square}, M_{\mathrm{w}}$

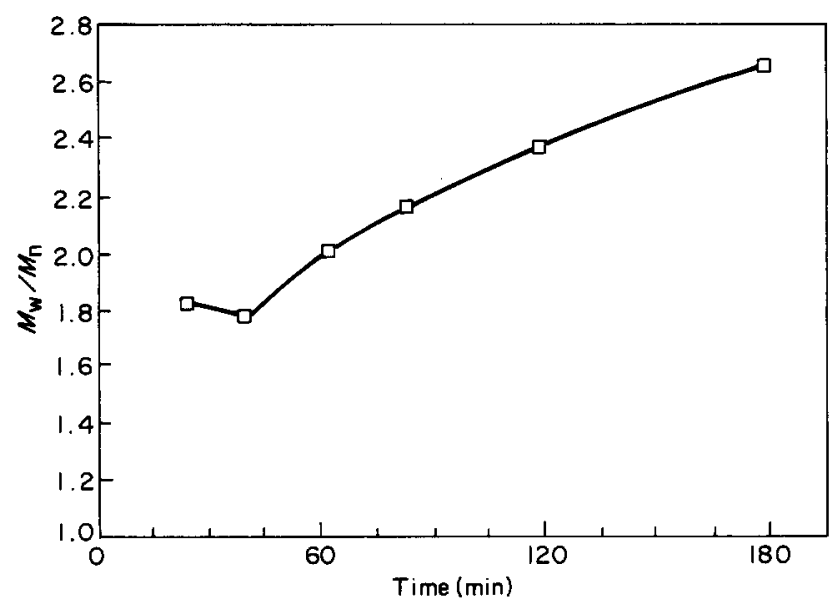

Figure 6 Change of molecular-weight distribution with time. Points correspond to the points in Figure 3

monomer addition the polymer yield becomes less than $100 \%$ as shown by a discrepancy from the straight line in Figure 3. This decreasing yield becomes larger at the end of the experiment where the reaction had lasted for $3 \mathrm{~h}$. This means that at the end of the reaction time not all added monomer is polymerized any more. The polymer concentration might be too high. It is also possible that the living head-groups have a short lifetime and that the reaction time is too long at this point. It was shown in the literature that PIB chains that were end-capped with chlorine can only slowly be reinitiated in the presence of $\mathrm{BCl}_{3}$.

Figure 4 shows the h.p.l.c. curves from each sample point in Figure 3. In Figure 5 we have plotted the molecular weight as a function of time. One sees an increase of molecular weight during the polymerization. The increase of molecular weight becomes less after $1 \mathrm{~h}$. This is also the time at which the yield becomes less than $100 \%$. In Figure 6 we see an increase of molecularweight distribution with time. If the polymerization was completely living during the whole experiment, an initially broad distribution would be expected, followed by a narrowing of the molecular-weight distribution with time. That the molecular-weight distribution increases with time means that some chains are still growing, but other chains have stopped growing or grow at a lower 
speed. This means that the polymerization under these conditions is not living. Chain transfer to monomer has not occurred, as was shown by the absence of double bonds in the i.r. and n.m.r. spectra.

\section{I.r. analyses}

I.r. measurements of the telechelics gave peaks that correspond with peaks for the polymer found in the literature ${ }^{28,29}$. Only a few extra peaks originating from the end-groups were found in the telechelics, a weak chlorine peak at $645 \mathrm{~cm}^{-1}$ and in some cases an olefinic peak at $890 \mathrm{~cm}^{-1}$.

\section{N.m.r. analyses}

The telechelics were all examined with n.m.r. to determine the ratio of chlorine groups relative to the amount of isobutylene. The chlorine itself could not be seen, but the peaks of the monomer adjacent to the chlorine were shifted enough to determine this chlorine content. The bulk $\mathrm{CH}_{2}$ and $\mathrm{CH}_{3}$ groups give peaks at respectively 1.11 and $1.42 \mathrm{ppm}$, while the end-groups show peaks at respectively 1.68 and $1.96 \mathrm{ppm}$.

\section{CONCLUSIONS}

It was shown that telechelic polyisobutylenes can be synthesized with chlorine end-groups. Both 2,5dimethoxy-2,5-dimethylhexane and 2,5-dimethoxy-2,5hexane diacetate can be used as initiators for this reaction. Even at low molecular weights a small molecular-weight distribution is obtained by using 2,5-dimethoxy-2,5dimethylhexane as initiator, $\mathrm{BCl}_{3}$ as catalyst and dichloromethane as solvent at $-40^{\circ} \mathrm{C}$. If the $\mathrm{BCl}_{3}$ /initiator ratio becomes too small, no polymerization occurs at all.

\section{ACKNOWLEDGEMENT}

This work is part of the research programme of the University of Twente and was financially supported by the Netherlands Innovative Research Program for Polymers (IOP).

\section{REFERENCES}

1 Butlerov, A. and Goryaniov, V. Chem. Ber. 1873, 6, 561

2 Otto, M. and Müller-Cunradi, M. (IG Farben) German Patent 641284,1931

3 Kennedy, J. P. and Smith, R. A. J. Polym. Sci., Polym. Chem. Edn 1980, 18, 1539

4 Nuyken, O., Pask, S. D., Vischer, A. and Walter, M. Makromol. Chem., Macromol. Symp. 1986, 3, 129 Baldwin, US Patent 3392154

6 Kennedy, J. P., Feinberg, S. C. and Huang, S. Y. Polym. Prepr. $1976,17,194$

7 Nagy, A., Faust, R. and Kennedy, J. P. Polym. Bull. 1986, 15, 411

8 Mishra, M. K. and Kennedy, J. P. J. Macromol. Sci., Chem. (A) 1987, 24(8), 933

9 Kaszás, G., Puskás, J. and Kennedy, J. P. Polym. Bull. 1987, 18, 123

10 Wang, B., Mishra, M. K. and Kennedy, J. P. Polym. Bull. 1987, 17, 205

11 Zsuga, M., Faust, R. and Kennedy, J. P. Polym. Bull. 1989, 21, 273

12 Kennedy, J. P., Feinberg, S. C. and Huang, S. Y. J. Polym. Sci., Polym. Chem. Edn 1977, 15, 2877

13 Puskás, J., Kaszás, G., Kennedy, J. P. and Kelen, T. J. Macromol. Sci., Chem. (A) 1982, 18(9), 1229

14 Toman, L., Pokorny, S. and Spevacek, J. J. Polym. Sci., Polym. Chem. Edn 1989, 27, 2217

15 Tessier, M., Hung, N. A. and Maréchal, E. Polym. Bull. 1981, 4, 111

16 Faust, R. and Kennedy, J. P. J. Polym. Sci., Polym. Chem. Edn 1987, 25, 1847

17 Nuyken, O., Chang, V. S. C. and Kennedy, J. P. Polym. Bull. $1981,4,61$

18 Kennedy, J. P., Chang, V. S. C., Smith, R. A. and Iván, B. J. Polym. Sci., Polym. Chem. Edn 1982, 20, 2809

19 Kennedy, J. P. and Storey, R. F. Org. Coat. Appl. Polym. Sci. $1982,46,182$

20 Iván, B., Kennedy, J. P. and Chang, V. S. C. J. Polym. Sci, Polym. Chem. Edn 1980, 18, 3177

21 Kennedy, J. P., Chang, V. S. C. and Guyot, A. Adv. Polym. Sci. 1982, 43, 1

22 Faust, R. and Kennedy, J. P. Polym. Bull. 1986, 15, 317

23 Faust, R. and Kennedy, J. P. J. Polym. Sci., Polym. Chem. Edn 1987, 25, 1874

24 Vogel, A. I. 'Practical Organic Chemistry', 3rd Edn, Longmans, London

25 Zsuga, M., Faust, R. and Kennedy, J. P. Polym. Bull. 1989, 21, 273

26 Faust, R., Nagy, A. and Kennedy, J. P. J. Macromol. Sci., Chem. (A) $1987,24(6), 595$

27 Plesk, P. H., Polangi, M. and Skinner, H. A. J. Chem. Soc. 1947, 257

28 Barnes, R. B., Liddel, U. and Williams, V. Z. Anal. Chem. 1943, 15,678

29 Lüttke, W. Angew. Chem. 1951, 63, 402 